\title{
The Role of Endotoxins in Methscopolamine Induced Ruminal Stasis in Calves
}

\author{
By $S$. Aiumlamai and H. Kindahl \\ Department of Obstetrics and Gynaecology and Department of Clinical Chemistry, \\ Faculty of Veterinary Medicine, Swedish University of Agricultural Sciences, Uppsala, Sweden.
}

\begin{abstract}
Aiumlamai, S. and H. Kindahl: The role of endotoxins in methscopolamine induced ruminal stasis in calves. Acta vet. scand. 1992, 33, 129-138. - Methscopolamine was used to induce ruminal stasis in calves. Clinical and blood biochemical parameters were studied to judge the possible role of gastro-intestinal endotoxins from Gramnegative bacteria. Two trials were carried out where one injection of $100 \mathrm{mg}$ and 3 consecutive injections of $70 \mathrm{mg}$ of methscopolamine were administered. The animals showed signs of ruminal stasis. General clinical signs and changes in blood biochemical parameters were similar to what is found in endotoxaemia or in induced ruminal acidosis. Relevant parameters such as prostaglandin $\mathrm{F}_{2 \alpha}$ metabolite, endotoxin, iron, zinc, calcium and glutamate dehydrogenase changed significantly indicating exposure of endotoxins.
\end{abstract}

prostaglandin; blood biochemical parameters.

\section{Introduction}

It is known that acute febrile diseases cause gastro-intestinal dysfunction in most animal species. In ruminants, marked inhibition of forestomach motility is a frequent complication in febrile diseases (van Miert 1987). Endotoxins from Gram-negative bacteria induce, in addition to fever, hypocalcaemia and provoke stasis of the forestomachs (Fredriksson 1984, Aiumlamai et al. 1990, Aiumlamai \& Kindahl 1990). In cows suffering from milk fever (hypocalcaemia) the rumen contractions are weak or even lacking. During milk fever the cows show clinical signs resembling those seen after administration of endotoxins, and the animals respond to calcium therapy. On the other hand during endotoxin induced fever and hypocalcaemia, calcium therapy does not restore forestomach motility (Lohuis et al. 1988). Also the ruminal lactic acidosis syndrome is always followed by ruminal stasis both in experimentally induced acidosis (Crichlow \& Chaplin 1985, Andersen \& Jarløv 1990, Aiumlamai et al. 1992) and in spontaneously occurring acidosis (Blood \& Radostits 1989). All these disease complexes have clinical and biochemical changes similar to what is found in endotoxaemia. Therefore, it is of great interest to study the hypothesis that gastrointestinal endotoxins from Gram-negative bacteria play a role in these disease syndromes. Ruminal stasis and hypomotility of the forestomach are typical signs of all abovementioned diseases. Thus, the studies of clinical and blood biochemical changes during ruminal stasis are of interest to relate to the findings of endotoxaemia and other diseases such as ruminal acidosis or parturient paresis. 
In the present study, methscopolamine was used to induce ruminal stasis. Methscopolamine is an anticholinergic agent such as atropine, scopolamine and benzetimide. It blocks ganglia in the gut and exerts antimuscarinic effects. Since methscopolamine is a more polar compound compared to the others, it does not cross the blood-brain barrier (Davis 1986) and is also less toxic. It has been reported that scopolamine has an effect as inhibitor of the prostaglandin synthesis (Dorigo \& Gaion 1984, Sumitomo et al. 1986, Adewunmi \& Ojewole 1987). Several reports also indicate that maintenance of smooth muscle tone, regulated by prostaglandins, is disturbed by scopolamine (Sanders \& Ross 1978).

\section{Materials and methods \\ Animals}

Four healthy female calves (A,B,C and D), 2 Swedish Red and White and 2 Swedish Friesian breed, aged 6 months, weighing about $100-110 \mathrm{~kg}$, were used in the 1 st study (A1D1). These four calves and an additional calf of Swedish Red and White breed (E2) were used in a 2 nd trial $\left(\mathrm{A}_{2}-\mathrm{E}_{2}\right)$. The time period between the 2 trials was one month. The animals were kept separated and fed with 0.1 $\mathrm{kg}$ /day of crushed oats, hay and water ad libitum throughout the study period.

\section{Methscopolamine}

Methscopolamine (Metylskopolamin without preservative, Apoteksbolaget, Umeå, Sweden) was prepared in a pharmaceutical preparation and considered as endotoxin free (in a Limulus test found to be less than 0.06 EU/ml (Friberger 1985)). The compound was injected subcutaneously in a dose of 100 $\mathrm{mg}$ in each calf after a $60 \mathrm{~h}$ control period in the 1st trial. In the 2 nd trial, 3 s.c. injections of $70 \mathrm{mg}$ were given at 0,8 and $16 \mathrm{~h}$ to each calf after a $24 \mathrm{~h}$ control period.

\section{Blood sampling}

Jugular vein blood samples were taken by puncture every $2 \mathrm{~h}$ for $60 \mathrm{~h}$ before and after methscopolamine injection in the 1st trial. In the 2 nd trial, blood samples were taken every $2 \mathrm{~h}$ for $24 \mathrm{~h}$ before and $84 \mathrm{~h}$ after the $1 \mathrm{st}$ of the 3 methscopolamine injections.

Five $\mathrm{ml}$ of jugular vein blood were withdrawn into heparinized Vacutainer tubes, 10 $\mathrm{ml}$ into plain Vacutainer tubes and $5 \mathrm{ml}$ into EDTA Vacutainer tubes (Becton and Dickinson, England). Plasma samples were centrifuged immediately. For serum tubes $30 \mathrm{~min}$ elapsed before centrifugation. Serum was transferred, with special care to avoid contamination of endotoxins from the environment, to another plain Vacutainer tube for endotoxin analysis and to a plastic tube for clinical chemistry analyses. All samples were stored at $-20^{\circ} \mathrm{C}$ until analyses were performed. Whole blood was immediately analysed for total white blood cell number (WBC) and blood was smeared for differential counts.

\section{Analytical methods}

15-Ketodihydro-PGF $\mathrm{P}_{2 \alpha}$ (PG), serum endotoxin $(\mathrm{ET})$, calcium $(\mathrm{Ca})$, zinc $(\mathrm{Zn})$, iron $(\mathrm{Fe})$, bile acids (BA), glutamate dehydrogenase $(\mathrm{GLDH})$, sodium $(\mathrm{Na})$, potassium $(\mathrm{K})$, total white blood cell count (WBC) and differential count were analysed by dividing the cells in polymorphonuclear (PMN) and mononuclear cells (MN) according to generally accepted methods and described in full in an accompanying paper (Aiumlamai et al. 1992). In the 1st trial in this study, endotoxin was not analysed and in the 2nd trial, total white blood cell and differential count were not evaluated. 


\section{Clinical examination}

Rectal body temperature (BT) was measured every time when blood was collected. Ruminal contractions (RC) were recorded every 2 $\mathrm{h}$ in daytime in the 1 st trial. In the 2 nd trial $\mathrm{RC}$ was recorded every $2 \mathrm{~h}$ in the daytime and during the first $40 \mathrm{~h}$ after the 1st injection of methscopolamine.

\section{Statistical analysis}

In the 1 st trial (1 injection of methscopolamine), differences of all parameters, in every $12 \mathrm{~h}$ interval (7.00 am-7.00 pm), from individual animals, were evaluated by analysis of variance (the Statgraphics Version 4.0, STSC, Inc.) and a confidence interval test was used to compare means, separately for the control and experimental periods. Then, the values from the experimental period for every $12 \mathrm{~h}$ interval were compared with the values of the respective control period by Student's $t$ test. In the 2 nd trial of 3 injections of methscopolamine, $24 \mathrm{~h}$ samples during the control period were used to compare with every $12 \mathrm{~h}$ interval samples during the experimental period $(84 \mathrm{~h})$ by analysis of variance in each individual animal and a confidence interval test was used to compare means. To be judged as significant changes, the values must be out of assay variation and significantly altered when compared to the control period of the respective time and/or to different parts of the experimental periods of the 1st trial. In the 2 nd trial, the same criteria were used to compare the control period to the different parts of the experimental period. In addition, the normal physiological ranges in healthy cattle (reference values) of these parameters were also used to consider the biological importance. This procedure does not relate to $\mathrm{pH}, \mathrm{RC}$ and $\mathrm{BT}$, where the significance was judged from comparisons between the control periods and the variation within the experimental periods.

\section{Results \\ Control period}

Both in the 1st and 2nd trials, during the control periods, all animals were clinically normal. In the 1st trial, the changes of all parameters were evaluated of each individual animal, in every $12 \mathrm{~h}$ interval during the control period $(60 \mathrm{~h})$. Rectal body temperature was significantly increased in 2 animals: animal $\mathrm{A}_{1}$ showed increased BT in daytime compared to during the night and animal $D_{1}$ showed the highest BT 25-36 $\mathrm{h}$ after the control period started. There was no change of $\mathrm{BT}$ in the other animals. The levels of RC, $\mathrm{PG}, \mathrm{Ca}, \mathrm{Zn}, \mathrm{BA}, \mathrm{Na}$ and WBC were not significantly changed during the control period and $\mathrm{Zn}, \mathrm{Na}$ and $\mathrm{WBC}$ as well as $\mathrm{Ca}$ values were within the reference range. However, $\mathrm{Ca}$ values in animal $\mathrm{D}_{1}$ were higher than the reference range. As regards $\mathrm{Fe}$ there were no significant changes in animals $A_{1}, C_{1}$ and $D_{1}$. The values for animals $A_{1}$ and $C_{1}$ were however higher than the reference range. In animal $B_{1}, F e$ levels were significantly decreased during the long period of frequent blood sampling, but the levels stayed within the reference range. The changes of GLDH were inconsistent, animals $A_{1}$ and $B_{1}$ showed no significant changes, animal $C_{1}$ showed a significant increase and animal $D_{1}$ showed a decrease. The levels of $\mathrm{K}$ showed a tendency to increase during the $37-48 \mathrm{~h}$ period after the start of the collection of samples in all animals but all values were within the reference range.

\section{Experimental period}

In the 1st trial, after the injection of $100 \mathrm{mg}$ of methscopolamine, ruminal contractions ceased in all animals (within $1 \mathrm{~h}$ ) and the left 
flank showed signs of ballooning like during bloat. They stopped eating within $2 \mathrm{~h}$ after injection, showed signs of discomfort, difficult breathing, they laid down and sometimes kicked at their belly. These clinical signs lasted about 10 to $12 \mathrm{~h}$. About 20 to $24 \mathrm{~h}$ after injection, the animals were quite normal and started to eat and ruminal contractions were again normal. In the 2 nd trial after the 1 st injection of $70 \mathrm{mg}$ of methscopolamine, all animals showed similar clinical signs as during the 1st trial. The signs remained until the 2nd injection after which the clinical signs became more severe. The signs remained until 12 to $14 \mathrm{~h}$ after the last injection. The animals started to eat and ruminal contractions became normal.

Tables 1 and 2 summarize the changes of all parameters seen in the 1 st and 2 nd trials.

Ruminal contractions were significantly decreased immediately after injection in both trials in all animals. In the 1 st trial ruminal stasis lasted during 0-12 $\mathrm{h}$ after injection in all animals and in the 2nd trial, during 0-36 $\mathrm{h}$ in animals $B_{2}, C_{2}, D_{2}$ and $E_{2}$ and $0-48 \mathrm{~h}$ in animal $A_{2}$ calculated after the 1 st injection.
In the 1st trial, rectal body temperature showed a significant increase in animal $D_{1}$ during 13-36 $\mathrm{h}$ after injection and a tendency to increase in animal $\mathrm{B}_{1}$ during $25-36 \mathrm{~h}$ after injection. There was no change in the other animals. In the 2nd trial, BT was significantly increased in animals $A_{2}, B_{2}$ and $E_{2}$ during 49$72 \mathrm{~h}, 13-24 \mathrm{~h}$ and $25-60 \mathrm{~h}$ after the 1 st injection, respectively.

Endotoxin was analysed in the 2nd trial, animal $E_{2}$ showed a tendency to increase during $0-24 \mathrm{~h}$ and was then followed by a significant increase during 37-48 $\mathrm{h}$ and 73-84 $\mathrm{h}$ after the 1st injection. Animals $\mathrm{C}_{2}$ and $\mathrm{D}_{2}$ showed a tendency to increase during $0-12 \& 37-72 \mathrm{~h}$ and 13-24 \& 73-84 $\mathrm{h}$ after the 1 st injection, respectively. Animals $A_{2}$ and $B_{2}$ showed no significant changes, however animal $B_{2}$ had spurious elevations both in periods $13-24 \mathrm{~h}$ and $49-72 \mathrm{~h}$ after the 1 st injection.

Prostaglandin levels were significantly increased in animal $D_{1}$ during $0-12 \mathrm{~h}$ and then showed a tendency to decrease 13-36 h after injection, in animal $A_{1}$ PG showed a tendency to increase during $13-24 \mathrm{~h}$ and a tendency to decrease during $37-48 \mathrm{~h}$ after

Table 1. A summary of the changes in clinical and blood biochemical parameters seen in experimentally induced ruminal stasis in calves (1 injection of methscopolamine, $100 \mathrm{mg}$ s.c.).

\begin{tabular}{lcccc}
\hline Parameters & $\mathrm{A}_{1}$ & $\mathrm{~B}_{1}$ & $\mathrm{C}_{1}$ & $\mathrm{D}_{1}$ \\
\hline RC & - & - & - & - \\
BT & 0 & $(+)$ & 0 & + \\
PG & $(+)(-)$ & $(-)$ & $(-)$ & $+(-)$ \\
Ca & $0^{\mathrm{a}}$ & $0^{\mathrm{a}}$ & $0^{\mathrm{a}}$ & $0^{\mathrm{a}}$ \\
Zn & $(-)^{\mathrm{a}}$ & $(-)^{\mathrm{a}}$ & $(-)^{\mathrm{a}}$ & $(-)^{\mathrm{a}}$ \\
Fe & $-\mathrm{b}$ & $-\mathrm{b}^{\mathrm{b}}$ & $-\mathrm{b}$ & - \\
BA & - & - & - & $(-)$ \\
GLDH & $(+)$ & + & $(-)+$ & - \\
Na & $0^{\mathrm{a}}$ & $0^{\mathrm{a}}$ & $0^{\mathrm{a}}$ & $(-)^{\mathrm{b}}$ \\
K & $(-)^{\mathrm{b}}$ & $(-)^{\mathrm{a}}$ & $(-)^{\mathrm{b}}$ & $(+)^{\mathrm{a}}$ \\
WBC & $(+)^{\mathrm{a}}$ & $(+)^{\mathrm{a}}$ & $(+)^{\mathrm{a}}$ & $(-)^{\mathrm{a}}$ \\
MN & $(-)^{\mathrm{a}}$ & $(-)^{\mathrm{a}}$ & $(-)^{\mathrm{a}}$ & $(+)^{\mathrm{a}}$ \\
PMN & $(+)^{\mathrm{a}}$ & $(+)^{\mathrm{a}}$ & $(+)^{\mathrm{a}}$ & \\
\hline
\end{tabular}

Key for signs: Please see Table 2. 
Table 2. A summary of the changes in clinical and blood biochemical parameters seen in experimentally induced ruminal stasis in calves ( 3 injections of methscopolamine, $70 \mathrm{mg}$ s.c. in each injection).

\begin{tabular}{|c|c|c|c|c|c|}
\hline Parameters & A2 & B2 & $\mathrm{C} 2$ & D2 & E2 \\
\hline $\mathrm{RC}$ & - & - & - & - & - \\
\hline BT & + & + & 0 & 0 & + \\
\hline ET & 0 & 0 & $(+)$ & $(+)$ & + \\
\hline PG & 0 & $(+)$ & $(+)$ & + & + \\
\hline $\mathrm{Ca}$ & $-^{a}$ & -a & $-{ }^{a}$ & $-^{\mathrm{a}}$ & $-^{a}$ \\
\hline $\mathrm{Zn}$ & - b & $-^{\mathbf{b}}$ & $-^{a}$ & $-^{\mathrm{a}}$ & - b \\
\hline $\mathrm{Fe}$ & $-\mathrm{b}$ & $-\mathrm{b}$ & $-{ }^{\mathrm{b}}+\mathrm{b}$ & $-\mathrm{b}+\mathrm{b}$ & $-^{\mathrm{b}}$ \\
\hline BA & -+ & -+ & - & 0 & -+ \\
\hline GLDH & $(-)+$ & - & -+ & -+ & - \\
\hline $\mathrm{Na}$ & $0^{\mathrm{a}}$ & $0^{\mathrm{a}}$ & $0^{\mathrm{a}}$ & $0^{\mathrm{a}}$ & $0^{\mathrm{a}}$ \\
\hline $\mathrm{K}$ & $-b$ & $-b$ & 0 & $-\mathrm{b}$ & $-\mathrm{b}$ \\
\hline
\end{tabular}

+ Indicates significant increase $(\mathrm{p}<0.05)$, - indicates significant decrease $(\mathrm{p}<0.05)$ and 0 indicates no significant changes. ( ) indicates a tendency to increase or decrease. Superscript "a" indicates that the values are in the normal reference range and superscript " $b$ " indicates that the values are out of the normal range (if no superscript is given it means that no reference range is described for that parameter in cattle). Two signs in 1 cell mean that both events occurred. The reference ranges of these parameters are used in Department of Clinical Chemistry, Faculty of Veterinary Medicine, Swedish University of Agricultural Sciences, Uppsala, Sweden.

injection in the 1 st trial. In other $2\left(B_{1}\right.$ and $\mathrm{C}_{1}$ ), PG had a tendency to decrease during 25-36 $\mathrm{h}$ and 37-48 h, respectively, after injection. In the 2nd trial, PG was significantly increased in animals $D_{2}$ and $E_{2}$ during $0-12 \mathrm{~h}$ and 13-24 $\mathrm{h}$ after the $1 \mathrm{st}$ injection, respectively. In animals B2 and C2, PG levels showed a tendency to increase during $49-84 \mathrm{~h}$ and $13-$ $24 \& 73-84 \mathrm{~h}$, respectively, after the 1 st injection. There was no change in animal $\mathrm{A}_{2}$.

The levels of Ca did not show any significant changes in the animals of the 1 st trial. However, during 6-12 $\mathrm{h}$ after injection, low levels were recorded in all of them (a decrease of about $10 \%$ ). In the 2 nd trial, Ca levels were significantly decreased in all animals, starting immediately from the 1 st injection to the end of the study in animals $A_{2}, C_{2}$ and $D_{2}$ and during 0-24 $\mathrm{h}$ and 49-60 $\mathrm{h}$ after the 1st injection in animals $B_{2}$ and $E_{2}$. The $C a$ values were within the reference range in all animals in both studies.

In the 1st trial, the levels of $\mathrm{Zn}$ showed a tendency to decrease within the reference range in all animals during 13-36 $\mathrm{h}$ in animals $\mathrm{A}_{1}$ and $B_{1}, 13-48 \mathrm{~h}$ and $13-24 \mathrm{~h}$ in animals $\mathrm{C}_{1}$ and $\mathrm{D}_{1}$, respectively. In the $2 \mathrm{nd}$ trial, $\mathrm{Zn}$ levels were significantly decreased in all animals during 13-36 $\mathrm{h}$ in animals $\mathrm{A}_{2}$ and $\mathrm{C}_{2}, 0-36 \mathrm{~h}$ in animals $B_{2}$ and $D_{2}$ and $13-48 \mathrm{~h}$ in animal $E_{2}$. The levels of $\mathrm{Zn}$ were below the reference range in animals $A_{2}, B_{2}$ and $E_{2}$, and within the normal range in animals $\mathrm{C}_{2}$ and $\mathrm{D}_{2}$.

The levels of $\mathrm{Fe}$ were significantly decreased in all animals in the 1st trial and the values were below the reference range. The levels significantly decreased during 13-48, 0-48, 060 and $0-48 \mathrm{~h}$ in animals $\mathrm{A}_{1}, \mathrm{~B}_{1}, \mathrm{C}_{1}$ and $\mathrm{D}_{1}$, respectively. Similar findings were found in 
the 2nd trial with lower levels found in all animals, the significant decrease occurred during 0-72 $\mathrm{h}$ in animals $\mathrm{A}_{2}$ and $\mathrm{E}_{2}, 0-60,13-$ 48 and $0-60 \mathrm{~h}$ in animals $\mathrm{B}_{2}, \mathrm{C}_{2}$ and $\mathrm{D}_{2}$, respectively, after the 1 st injection. In animals $C_{2}$ and $D_{2}$ the levels of $F e$ also increased significantly later during 61-84 h after injection.

Serum bile acids showed a significant decrease in animals $A_{1}, B_{1}$ and $C_{1}$ and a tendency to decrease in animal $\mathrm{D}_{1}$ during 13-24, $0-24,0-36$ and $0-24 \mathrm{~h}$, respectively. In the 2 nd trial, BA levels were significantly decreased and then increased in animals $A_{2}, B_{2}$ and $E_{2}$, animal $\mathrm{C}_{2}$ showed only a significant decrease and there was no change in animal $D_{2}$. The decrease of the BA levels occurred during 25-36, 0-36, 0-36 and 0-12 \& 25-36 $\mathrm{h}$ after the 1st injection, in animals $A_{2}, B_{2}, C_{2}$ and $E_{2}$, respectively.

In the 1st trial, the activity of GLDH was significantly increased in animals $B_{1}$ during 0-24 $\mathrm{h}$ and $\mathrm{C}_{1}$ during 49-60 $\mathrm{h}$ and showed a tendency to increase in animal $\mathrm{A}_{1}$ during 13-24 \& 49-60 h but significantly decreased in animal $\mathrm{D}_{1}$ during 13-60 $\mathrm{h}$ after injection. Animal $\mathrm{C}_{1}$ showed also a tendency to decrease during 25-48 $\mathrm{h}$ after injection and then followed by the significant increase. In the 2nd trial, in animals $\mathrm{C}_{2}$ and $\mathrm{D}_{2}$, GLDH showed a significant decrease during 13-48 $\mathrm{h}$ and 13-24 $\mathrm{h}$ after the 1 st injection then followed by a significant increase during 61-84 $\mathrm{h}$ and 25-60 h, respectively. Animal $\mathrm{A}_{2}$ showed a tendency to decrease in the activity of GLDH during 25-48 $\mathrm{h}$ and followed by a significant increase during $49-84 \mathrm{~h}$ after the 1 st injection. The activity of GLDH was significantly decreased in animals $\mathrm{B}_{2}$ during 13-72 $\mathrm{h}$ and $\mathrm{E}_{2}$ during 0$84 \mathrm{~h}$ after injection.

The levels of $\mathrm{Na}$ both in the 1st and 2nd trials showed no significant changes and the values were within the reference range. The levels of $\mathrm{K}$ showed a tendency to decrease during $0-12 \mathrm{~h}$ after injection in all animals with the levels below the reference range, except in animal $B_{1}$ with levels still within the reference range. In the 2 nd trial, $K$ levels were significantly decreased in animals $A_{2}, B_{2}, D_{2}$ and $\mathrm{E}_{2}$ during $0-12 \mathrm{~h}$ after the 1 st injection and no change in animal $\mathrm{C}_{2}$. The levels were below the reference range in all animals.

The changes of WBC, PMN and MN were evaluated only in the 1 st trial, and all animals showed similar patterns. WBC showed a small increase during 6-14 $\mathrm{h}$ after injection and there was a shift in WBC in that PMN increased in levels concomitant with a decrease of $\mathrm{MN}$ during the same period.

\section{Discussion}

During the control period in the 1st trial, there were no significant changes in most of the studied parameters. A few parameters changed inconsistently e.g. in 1 animal GLDH and Fe showed a significant decrease during the long period of frequent blood sampling. In a previous study where the same blood sampling frequency was employed more pronounced changes were seen of some biochemical parameters in the control period as well as more obvious day and night differences in body temperature (Aiumlamai et al. 1992). The animals in that study were younger and the relative blood loss was greater. The changes during the control periods have been considered in the interpretation of the results from both trials.

In the 1st and 2nd trials, all animals behaved very similarly in most of the recorded changes both regarding clinical and blood biochemical parameters. No results from the 2 trials, except for prostaglandin metabolite levels, are contradicting. If 3 injections are used, a more pronounced and prolonged 
response is seen as compared to 1 injection. Immediately after injection of methscopolamine, a ruminal stasis appeared in all animals in both trials during about $12 \mathrm{~h}$ after 1 injection and $48 \mathrm{~h}$ after 3 injections. This drug did not show any clinical side effects and was not harmful to the animals. They recovered and were clinically normal after the experiment had finished.

The general trends of clinical and blood biochemical changes, demonstrated in this study, showed evidence of that ruminal stasis is linked to resorption of endotoxins from the gastro-intestinal tract causing endotoxaemia/endotoxicosis. Leukocytosis and shift of $\mathrm{WBC}$, an increase in number of PMN and concomitantly a decrease in the number of $\mathrm{MN}$, were found in all animals. These changes accord well, with what has been demonstrated after injection of low doses of endotoxin (Yagoda et al. 1990 a,b). In calves overfed with oats, causing ruminal acidosis and stasis, similar changes in clinical and blood biochemical parameters were seen (Aiumlamai et al. 1992). It was concluded in that study that a low amount of endotoxins might have been resorbed from the gastrointestinal tract. Most of the studied parameters discussed below support the hypothesis that endotoxins are resorbed in low amounts to the blood circulation also after methscopolamine induced stasis: increase in body temperature, endotoxins, prostaglandin metabolite levels and GLDH as well as decrease in iron, calcium, zinc and bile acids. Similar findings were found after endotoxin injection (Aiumlamai et al. 1990, Aiumlamai \& Kindahl 1990). Furthermore, the decrease in ruminal contractions in this study caused by methscopolamine might later on have been enhanced by the effect of endotoxins. In the 2nd trial, the endotoxin levels showed a significant increase or a tendency to increase in 3 out of 5 animals and 1 had some spurious elevations. The increase in the body temperature is also a strong support to that endotoxins have been resorbed, since endotoxins are known as strong pyrogens (Milton 1982, Dinarello 1983). Both trials showed significant or tendencies of increases of BT, 2 out of 4 after 1 injection and 3 out of 5 after 3 injections. Prostaglandin $\mathrm{F}_{2 \alpha}$ is a dominating endotoxin-mediated product and is a very reliable parameter for estimating the effect of endotoxins on the arachidonic acid cascade (Fredriksson et al. 1985, Aiumlamai et al. 1990). After 1 injection in the present study, PG levels increased in 1 animal and showed a tendency to increase in 1 animal followed by a tendency to decrease and in the 2 remaining ones it showed a tendency to decrease. Methscopolamine has been used as a muscarinic blocking agent causing relaxation of the gastro-intestinal tract but it has also been discussed as one in a group of inhibitors of prostaglandin synthesis (Dorigo \& Gaion 1984, Adewunmi \& Ojewole 1987). However, its potency to inhibit the prostaglandin biosynthesis is not known. This can explain the decrease of PG levels as seen in the 1st trial. However in the second trial PG showed an increase in four out of five animals. This might be explained by the fact that in the 2nd trial the ruminal stasis was both more severe and prolonged compared to the 1 st trial, probably resulting in a more pronounced endotoxaemia. In that situation it is possible that the inhibiting effect of methscopolamine is not enough to block the synthesis of prostaglandin. Even though the animals were treated with a substance inhibiting PG-formation the net result will be increased levels of the PG-metabolite. Thus, from the finding of PG levels it can also be concluded that an endotoxaemic state has occurred. The levels were not highly 
increased as found after injection of higher doses of endotoxin (Fredriksson et al. 1985, Kindahl et al. 1990) which also can impair reproductive performance. However, this low amount of PG release in ruminal stasis which was also found in acidosis/overfeeding (Aiumlamai et al. 1992) could possibly impair reproductive function when it turns into a circulus vitiosus.

The decreases of $\mathrm{Fe}, \mathrm{Zn}$ and $\mathrm{Ca}$ accord well with the findings during experimentally induced endotoxaemia (Luthman et al. 1990, Aiumlamai \& Kindahl 1990) as well as in experimentally induced acidosis (Andersen \& Jarløv 1990, Aiumlamai et al. 1992). The clear profile of changes of these parameters makes it likely that endotoxins were resorbed from the alimentary tract to the blood circulation. The absence of changes in $\mathrm{Na}$ and the decrease in $\mathrm{K}$ levels are similar to the results obtained after endotoxin injection and induced ruminal acidosis (Aiumlamai \& Kindahl 1990, Aiumlamai et al. 1992).

Bile acids decreased in the 1st trial and in the 2 trial BA first decreased and then increased above the basal levels in 3 of the animals. The low levels of bile acids found are probably due to the alimentary stasis and reflect the decreased enterohepatic circulation. This will lead to less bile acids available to the peripheral circulation (Olsson 1986, Aiumlamai et al. 1990). However, the reason for the increase later on is not known.

Two animals in the 1st trial and all in the 2nd one showed initially a decrease in the activity of GLDH. A decrease was also seen in experimentally induced acidosis/ruminal stasis (Aiumlamai et al. 1992). This decrease cannot be fully explained but seems to be linked to the induced stasis and/or some effect on the liver cells. In most of the animals an increase in the GLDH activity is seen later on. This can be due to an impaired liver function and also to a more direct liver cell damage. Mullen (1976) described that GLDH is a good indicator for damaged hepatocytes although small increases of the enzyme were found.

Interestingly, the alimentary stasis in the calves demonstrated clinical and blood biochemical findings similar to what is found in endotoxaemia. Many disease syndromes such as acidosis and parturient paresis have signs of ruminal stasis as well as of endotoxaemia. During stasis of the gastro-intestinal tract, it might be possible that endotoxin from Gramnegative bacteria can be resorbed into the blood circulation, cause related pathophysiological changes and thus being a major component in these disease complexes. The changes of the parameters demonstrated in this study were less dramatic compared to experimentally induced endotoxaemia but more pronounced than during acidosis/overfeeding. The interpretation of the results can be complicated due to that methscopolamine has dual effects - induction of gastro-intestinal stasis and resorption of endotoxins versus inhibition of prostaglandin synthesis. The animals also showed significant changes in most of the relevant parameters such as prostaglandin, endotoxin, iron, zinc, calcium, GLDH which indicates the exposure of endotoxins. In conclusion, it showed that the ruminal stasis induced the clinical and blood biochemical profiles as found in endotoxaemia and thus it seems likely that endotoxins are resorbed from the alimentary tract during its stasis. These findings also show, that endotoxins complicate many disease complexes which have clinical signs of ruminal stasis/hypomotility of the alimentary tract, and as a matter of fact that endotoxins might be the major component in these diseases. 


\section{Acknowledgements}

This study was supported by grants from the Swedish Council for Forestry and Agricultural Research. The authors would like to express their sincere thanks to Assoc. Prof. Örjan Eriksson and Dr. Lena Kulander for endotoxin analysis and to Assoc. Prof. Gunnar Fredriksson for his constructive and fruitful criticism. The Department of Animal Breeding and Genetics is acknowledged for lending us the animals. The Dairy Farming Promotion Organization of Thailand is gratefully acknowledged for the leave of absence of S. Aiumlamai.

\section{References}

Adewunmi CO, Ojewole JAO: Effects of oxamniquine on chick isolated esophagus. Meth. find. exptl. clin. Pharmacol. 1987, 9, 233-236.

Aiumlamai S, Fredriksson $G$, Kindahl H, Edqvist L-E, Kulander L, Eriksson Ö: Endotoxin concentrations in the blood following intravenous injection and effect on prostaglandin $F_{2 \alpha}$ release, calcium and bile acids in goats. Res. vet. Sci. 1990, 48, 190-195.

Aiumlamai $S$, Kindahl $H$ : Clinical and blood biochemical changes during induction of endotoxaemia in heifers. Acta vet. scand. 1990, 31, 501504.

Aiumlamai S, Kindahl H, Fredriksson G, Edqvist $L-E$, Kulander L, Eriksson $\ddot{O}$ : The role of endotoxins in induced ruminal acidosis in calves. Acta vet. scand. 1992, 33, 117-127.

Andersen PH, Jarløv $N$ : Investigation of the possible role of endotoxin, TXA2, PGI2, and PGE2 in experimentally induced rumen acidosis in cattle. Acta vet. scand. 1990, 31, 27-38.

Blood DC, Radostits OM: Acute carbohydrate engorgement of ruminants (rumen overload). In: Veterinary Medicine 7th ed., 1989, pp. 246253.

Crichlow EC, Chaplin RK: Ruminal lactic acidosis: Relationship of forestomach motility to nondissociated volatile fatty acids levels. Amer. J. vet. Res. 1985, 46, 1908-1911.

Davis LE: Drugs affecting the digestive system. In: Howard JL (ed.): Current Veterinary Therapy 2, Food Animal Practice 1986, pp 760-763.

Dinarello CA: Molecular mechanisms in endotoxin fever. Agents Actions 1983, 13, 470-486.

Dorigo P, Gaion RM: Cholinergic mechanism of sodium nicotinate-induced contractions in rat and guinea-pig descending colon. Arch. int. Pharmacodyn. 1984, 268, 287-300.
Fredriksson $G$ : Some reproductive and clinical aspects of endotoxins in cows with special emphasis on the role of prostaglandins. Acta vet. scand. 1984, 25, 365-377.

Fredriksson $G$, Kindahl $H$, Edqvist L-E: Endotoxin-induced prostaglandin release and corpus luteum function in goats. Anim. Reprod. Sci. 1985, 8, 109-121.

Friberger $P$ : The design of a reliable endotoxin test. In: ten Cate J W, Büller H R, Sturk A, Levin J, (eds.): Bacterial Endotoxins: Structure, biomedical significance, and detection with the limulus amebocyte lysate test. Alan R Liss, 1985, pp. 139-149.

Kindahl H, Odensvik K, Fredriksson $G$, Cort $N$, Daels P, Hughes J, Stabenfeldt GH: Effects of endotoxins on prostaglandin biosynthesis and reproductive function in farm animals. Proc. 4 th Congress of Europ. Ass. Vet. Pharmacol. Toxicol., Budapest, Aug. 28-Sept. 2, 1988 Simon F, Lees P, Semjén G, (eds.), 1990, pp. 205-212.

Lohuis JACM, Verheijden JHM, Burvenich $C$, van Miert ASJPAM: Pathophysiological effects of endotoxins in ruminants. Vet. Quart. 1988, 10, 117-125.

Luthman J, Kindahl H, Jacobsson S-O: The influence of flunixin on the response to Salmonella typhimurium endotoxin in calves. Acta vet. scand. 1990, 31, 295-300.

Milton AS: Prostaglandins and fever. Trends in Pharmacological Sciences 1982, 3, 490-492.

Mullen PA: The diagnosis of liver dysfunction in farm animals and horses. Vet. Rec. 1976, 99, 330-334.

Olsson $T$ : Serum bile acids in hypocalcaemic dairy cows. 6th Int. Conf. Prod. Disease in Farm Animals, Belfast, 1986, pp. 20-23.

Sanders $K M$, Ross $G$ : Effects of endogenous prostaglandin $\mathrm{E}$ on intestinal motility. Amer. J. Physiol. 1978, 234, E204-E208.

Sumitomo K, Ikeda K, Nagasaki A: The use of prostaglandin $\mathrm{F}_{2 \alpha}$ and scopolamine-N-butylbromid in anorectal manometric diagnosis. Z. Kinderchir. 1986, 41, 344-347.

van Miert ASJPAM: Fever, anorexia and forestomach hypomotility in ruminants. Vet. Res. Comm. 1987, 11, 407-422.

Yagoda CR, Bylund-Fellenius A-C, Kindahl $H$ : Some effects of Gram-negative bacterial endotoxin and its importance as a contaminator of biological preparations. Acta vet. scand. 1990a, 31, 193-206. 
Yagoda CR, Bylund-Fellenius AC, Adner N, Kindahl $H$ : Biological responses of sheep treated with endotoxin-contaminated superoxide dismutase and endotoxin preparations. Acta vet. scand. 1990b, 31, 207-217.

\section{Sammanfattning}

Betydelse av endotoxiner?

II. Vid metylskopolamininducerad våmstas hos kalv. Metylskopolamin användes för att inducera våmstas hos kalv. Kliniska och blodkemiska parametrar studerades för att utvärdera möjligheten av resorp- tion av endotoxiner från Gram-negativa bakterier i mag-tarmkanalen. Två försöksserier utfördes med metylskopolamin: $100 \mathrm{mg}$ gavs som engångsdos respektive 3 upprepade injektioner med $70 \mathrm{mg}$. Djuren visade tydliga tecken på våmstas. Den kliniska bilden och förändringar i blodkemiska parametrar är likartade dem som syns vid endotoxinämi eller vid inducerad våmacidos. Viktiga parametrar som prostaglandin $\mathrm{F}_{2 \alpha}$ metabolit, endotoxin, järn, zink, kalcium och glutamatdehydrogenas förändrades signifikant, vilket indikerar att djuren exponerats för endotoxiner.

(Received October 2, 1991; accepted October 11, 1991).

Reprints may be requested from: Hans Kindahl, Department of Obstetrics and Gynaecology, Swedish University of Agricultural Sciences, Box 7039, S-750 07 Uppsala, Sweden. 